Jurnal Pendidikan Sosial Keberagaman

Print-ISSN 2355-4622 Online-ISSN 2622-9021

Vol. 6, No. 1, Oktober-Maret 2019, hh. 18-26

https://juridiksiam.unram.ac.id/index.php/juridiksiam

\title{
PENGARUH PENERAPAN MODEL PEMBELAJARAN COOPERATIVE LEARNING TIPE TIME TOKEN ARENDS BERBANTUAN INDEX CARD MATCH TERHADAP HASIL BELAJAR PPKn SISWA KELAS XI SMKN 4 MATARARM
}

\author{
Rokyal Aini ${ }^{1}$, Ismail ${ }^{2}$, Zubair $^{3}$ \\ ${ }^{1}$ Mahasiswa prodi PPKn, ${ }^{23}$ Dosen Jurusan Pendidikan IPS \\ Fakultas Keguruan dan Ilmu Pendidikan Universitas Mataram \\ Email: ismail.fkipgmail.com
}

\begin{abstract}
ABSTRAK
Tujuan penelitain ini adalah untuk mengetahui ada tidaknya pengaruh modelCooperative Learning tipe Time Token Arends berbantuan Index Card Match terhadap hasil belajar siswa kelas XI pada mata pelajaran PPKn di SMKn 4 Mataram. Penelitian ini merupakan jenis penelitianQuasi Eksperimen dengan rancangan NonEquavalen Control Group Design. Instrumen yang digunakan dalam penelitian ini adalah tes bentuk pilihan ganda sebanyak 30 soal yang telah memenuhi persyaratan instrumen penelitian untuk mengukur hasil belajar siswa. Hasil penelitian menunjukkan bahwa $\mathrm{t}_{\text {hitung }}=6.214^{-} \mathrm{t}$ tabel $=2.021$ pada taraf signifikasn $5 \%$. Artinya hasil penelitian menunjukkan bahwa ada pengaruh model Cooperative Learning tipe Time Token Arends berbantuan Index Card Match terhadap hasil belajar siswa kelas XI pada mata pelajaran PPKn di SMKn 4 Mataram.
\end{abstract}

Kata Kunci: Time Token Arends, Index Card Match, Hasil Belajar

\section{ABSTRACT}

The aim of this study is to know the impact of Cooperative LearningModel Of Time Token Arends Assist Index Card Match Toward Students Study Result In Civic Moral Education Class XI Subject At SMKN 4 Mataram. This research type is a Quasi Experiment with Non-Equivalent Control Group Design. In this research, the instrument that used is multiple choice tests consist of 30 items which have fulfilled the research instrument aimed to measure the studentsstudy result. The result of the study shows that ctunt $(6,214)^{-} \mathrm{t}$ table $(2,021)$ on the $5 \%$ level of significant, means that Cooperative Learninglodel Of Time Token Arends Assist Index Card Match Toward Students Study Result In Civic Moral Education Class XI Subject At SMKN 4 Mataram.

Keywords: Time Token Arends, Index Card Match, Students Study Result 


\section{PENDAHULUAN}

Pendidikan merupakan kebutuhan utama bagi setiap manusia, karena melalui pendidikan kita akan memiliki ilmu pengetahuan yang akan menjadikan generasi-generasi yang cerdas dan unggul. Dalam Undang-Undang RI No.20 tahun 2003 pasal 3 tentang Sistem Pendidikan Nasional, "Pendidikan dilakukan dalam rangka mencapai tujuan yang diharapkan bersama yakni untuk membentuk warga Negara yang cerdas, berakhlak mulia dan bertaqwa kepada Tuhan Yang Maha Esa”.

Salah satu mata pelajaran yang dapat mewujudkan tujuan di atas adalah mata pelajaran Pendidikan Pancasila dan Kewarganegaraan (PPKn).Menurut Darmadi (2013), Pendidikan Pancasila dan kewarganegaraan merupakan komponen pembelajaran yang memfokuskan pada pembentukan warga negara yang mampu memahami dan melaksanakan hak-hak dan kewajibannya untuk menjadi warga negara Indonesia yang cerdas, terampil, dan berkarakter.Proses pembelajaran PPKn dapat dikatakan berhasil apabila dapat mengembangkan potensi yang dimilikinya baik sikap pengetahuan, sikap, religius, sikap sosial, dan sikap keterampilan. Keberhasilan proses pembelajaran ini ditunjukkan dengan semakin meningkatnya hasil belajar siswa (dalam Wirdiati, K.2017: 2).

Berdasarkan pemaparan di atas, guru harus memperhatikan cara mengajar, tentunya dibutuhkan kemampuan guru dalam mengembangkan model pembelajaran yang memperlihatkan suatu pola pembelajaran tertentu, pola tersebut dapat terlihat kegiatan guru dan siswa dalam mewujudkan kondisi belajar yang menyebabkan terjadinya kegiatan belajar pada siswa (dalam Valentina, O. F, 2013:3). Fakta yang terjadi pada saat ini, pelaksanaan pembelajaran PPKn di kelas sering terjadi masalah yang erat kaitannya dengan proses pembelajaran yang kurang melibatkan siswa atau berpusat pada guru daripada mencari sendiri pengetahuan, keterampilan yang mereka butuhkan.

Ultaminingsih (2010: 2) menyatakan bahwa model pembelajaran yang digunakan oleh sebagian besar guru PPKn masih memakai model pembelajaran konvensional atau tradisional.Menurut Wina Sanjaya (dalam Ibrahim, 2017: 202) menyatakan bahwa pada pembelajaran konvensional siswa ditempatkan sebagai obyek belajar yang berperan sebagai penerima informasi secara pasif. Hal tersebut dapat dilihat juga dari hasil belajar siswa pada hasil ulangan Mid semester ganjil tahun ajaran 2017, dimana dari 30 siswa hanya 18 orang siswa yang mendapatkan nilai di atas 75 dan 12 orang siswa yang mendapatkan nilai kurang 75. Dalam artian bahwa banyak siswa yang mendapatkan nilai dibawah standar kelulusan yang telah ditetapkan. Untuk mencapai target kelulusan yang telah ditetapkan oleh sekolah yaitu 75 maka guru mengadakan kegiatan remedial atau tugas tambahan bagi siswa.

Berbagai permasalahan yang terjadi di atas berpengaruh terhadap hasil belajar siswa di duga dipengaruhi oleh beberapa faktor baik eksternal maupun internal. Ahmad Susanto (dalam Khusna,M, 2016:21) mengemukakan bahwa faktor-faktor yang mempengaruhi hasil belajar siswa yaitu faktor internal 
meliputi; kecerdasan, minat dan perhatian, motivasi belajar, ketekunan, sikap, kebiasaan belajar, serta kondisi fisik dan kesehatan. Sedangkan faktor eksternal ialah faktor yang berasal dari luar diri siswa yang mempengaruhi hasil belajarnya yaitu keluarga, sekolah, dan masyarakat. Selain itu, faktor-faktor dari luar yang mempengaruhi hasil belajar siswa pada mata pelajaran PPKn salah satunya adalah model pembelajaran yang belum tepat untuk meningkatkan hasil belajar siswa.

Dari faktor-faktor di atas, berupa model pembelajaran menjadi faktor dominan yang ikut menentukan hasil belajar siswa, tidak heran banyak siswa yang merasa bosan terhadap mata pelajaran PPKn, di tandai dengan kegiatan menyimak, menghafal, merangkum, tanpa adanya model pembelajaran yang membuat siswa menjadi lebih aktif. Salah satu model yang digunakan guru harus mampu merancang model pembelajaran dengan baik, namun hal tersebut tidaklah mudah untuk secara langsung memberikan perubahan terhadap siswa, guru memerlukan tenaga dan pikiran untuk merancang model pembelajaran agar semenarik mungkin sehingga membuat siswa menjadi aktif belajar, terutama untuk meningkatkan hasil belajar siswa, maka diperlukan penggunaan model pembelajaran yang tepat untuk meningkatkan hasil belajar siswa.

Salah satu model pembelajaran dapat diterapkan oleh guru untuk meningkatkan hasil belajar siswa pada proses pembelajaran PPKn adalah model pembelajaran Cooperative Learning tipe Time Token Arends berbantuan Index Card Match. Adapun yang dimaksud dengan model Time Token Arends:

"Menurut Budiyanto (2016:149) adalah model pembelajaran yang digunakan dengan tujuan agar siswa aktif berbicara", dan yang dimaksud dengan Index Card Match menurut Zaini, dkk (2008:67) media Index Card Match (mencari pasangan) adalah "model yang cukup menyenangkan yang digunakan untuk mengulang materi yang telah diberikan sebelumnya" (dalam Ningsih, N, 2014: 4).

Adapun beberapa kelebihan time tokenmenurut(Budiyanto, A, K (2016:149) sebagai berikut: (1) mendorong siswa untuk meningkatkan inisiatif dan partisipasi, (2) siswa tidak mendominasi pembicaraan atau diam sama sekali, (3) siswa menjadi aktif dalam kegiatan pembelajaran, (4) meningkatkan kemampuan siswa dalam berkomunikasi (aspek berbicara),SedangkanIndex Card Match menurut Zaini (2008:69), Dapat meningkatkan aktivitas belajar siswa, baik secara kognitif maupun fisik, Efektif sebagai sarana melatih keberanian siswa.

Bukti empiris berdasarkan hasil penelitian terdahulu menunjukkan bahwa model pembelajaran Cooperative Learning Tipe Time Token Arends berbantuan Index Card Match terhadap hasil belajar siswa. Adapun hasil-hasil penelitian terdahulu tentang penggunaan model pembelajaran Cooperative Learning Tipe Time Token Arends berbantuan Index Card Match antara lain: oleh Ma'ab (2015) pada mata pelajaran PKn yang menunjukkan bahwa terdapat perbedaan hasil belajar PKn antara siswa yang mengikuti pembelajaran dengan model pembelajaran Time Token Arendsdengan siswa yang mengikuti model pembelajaran konvensional..Penelusuran terhadap berbagai hasil penelitian yang lain dari jurnaldigunakan pada mata pelajaran Biologi dalam meningkatkan hasil belajar siswa. Adapun hasil penelitian yang dilakukan oleh 
Musyafar (2010), yang menunjukkan bahwa terdapat perbedaan hasil belajar Biologi antara siswa yang mengikuti pembelajaran dengan penerapan model pembelajaran Time Token Arends dengan menggunakan Media Kartu Indeks. Penelitian ini menggunakan jenis eksperimen semu sehingga masih ada peluang untuk peneliti melakukan penelitian dengan Time Token Arendsdan Index Card Match.

\section{METODE PENELITIAN}

Pendekatan yang digunakan dalam penelitian ini adalah pendekatan kuantitatif dengan jenis penelitian Quasi Eksperiment dengan rancanganNon-Equivalent Control Group Design. Quasi eksperiment didefinisikan sebagai eskperimen yang memiliki perlakuan, pengukuran dampak, unit eksperimen namun tidak menggunakan penugasan acak untuk menciptakan perbandingan dalam rangka menyimpulkan perubahan yang disebabkan perlakuan (Cook \& Campbell, 1979:4).

Design penelitian yang digunakan adalah Non-Equivalent Control Group Design. Dalam penelitian ini digunakan empat kelas, kelas dibagi dalam treatment group dan control group $\left(\mathrm{M}, \mathrm{X}_{1}, O\right),\left(\mathrm{M}, \mathrm{X}_{2}, O\right)$. Dapat dilihat pada tabel di bawah ini:

Tabel 1. Nonequivalen Control Group Design

\begin{tabular}{cccc}
\hline Kelompok & Pre-test & Perlakuan & Post-test \\
\hline Eksperimen & $\mathrm{O}_{1}$ & $\mathrm{X}$ & $\mathrm{O}_{2}$ \\
\hline Kontrol & $\mathrm{O}_{1}$ & - & $\mathrm{O}_{2}$ \\
\hline
\end{tabular}

Berdasarkan Tabel 1, kelas eksperimen dikenai variabel perlakuan peembelajaran Cooperative Learningtipe Time Token Arends berbantuan Index Card Matchdan kelas kontrol tidak dikenai perlakuan dengan jangka waktu yang sama dengan kelas eksperimen. Kemudian, kedua kelas tersebut dikenai pengukuran yang sama. Perbedaan hasil belajar siswa yang timbul dianggap bersumber dari variabel perlakuan. Pada akhir proses pembelajaran diberikan post-tes kepada kelas kontrol dan kelas eksperimen dengan menggunakan instrumen yang sama untuk mengetahui ada tidaknya pengaruh perlakuan terhadap hasil belajar siswa PPKn di SMKN 4 Mataram.

Instrumen pengumpulan data hasil belajar siswa pada Mata Pelajaran PPKn menggunakan instrumen test berupa pilihan ganda yang telah dilakukan uji validitas, reliabilitas, tingkat kesukaran, dan daya pembeda.hasil pengujian menunjukkan bahwa instrumen yang digunakan telah memnuhi kriteria instrumen yang baik.

Data yang diperoleh berdasarkan hasil penelitian, kemudian dianalisis dengan metode yang dikembangkan berdasarkan kajian penelitian kuantitatif. Analisis data menggunakan uji persayaratan analisis mencakup uji homogenitas dan uji normalitas data. Setelah itu menggunakan uji hipotesis dengan menggunakan uji $\mathrm{T}$. 
Vol. 6 No. 1, Oktober-Maret 2019, hh. 18-26

\section{HASIL DAN PEMBAHASAN}

\section{HASIL}

Deskripsi hasil ini mencakup hasil uji persyaratan analisis dan uji hipotesis.

\section{Uji Persyaratan Analisis}

Uji persyaratan analisis terdiri dari uji normalitas dan uji homogenitas. Uji homogenitas digunakan untuk menyamakan atau menghomogenkan kemampuan awal kedua kelompok sampel dengan menggunakan rumus uji-F. Sedangkan uji normalitas ini dilakukan bertujuan untuk mengetahui data berdistribusi normal atau tidak dengan menggunakan Chi Kuadrat. Hasil uji homogenitas tes awal dan tes akhir pada kelompok kelas eksperimen dan kelas kontrol dapat dilihat pada tabel 2 berikut:

Tabel 2. Hasil uji homogenitas tes awal

\begin{tabular}{cccccccc}
\hline Kelas & $\mathrm{N}$ & $\bar{x}$ & $S$ & $S^{2}$ & $F_{\text {hitung }}$ & $F_{\text {tabel }}$ & Keterangan \\
\hline \multirow{2}{*}{ Eksperimen } & 28 & 45.48 & 6.56 & 42.97 & \multirow{2}{*}{1,19} & \multirow{2}{*}{1,93} & Homogen \\
\cline { 1 - 5 } Kontrol & 28 & 40.24 & 6.01 & 36.16 & & & \\
\hline
\end{tabular}

Sumber:pengolahan data primer

Berdasarkan Tabel 1 di atas, dapat ditarik kesimpulan bahwa $F_{\text {hitung }}(1,19)<\mathrm{F}_{\text {tabel }}(1,93)$ pada taraf signifikan 5\%, maka kedua sampel memiliki varian yang homogen. Artinya bahwa analisis dengan uji parametrik memenuhi syarat.

Tabel 3 Hasil uji homogenitas tes akhir

\begin{tabular}{|c|c|c|c|c|c|c|c|}
\hline Kelas & $\mathrm{N}$ & $\bar{x}$ & $S$ & $S^{2}$ & $F_{\text {hitung }}$ & $F_{\text {tabel }}$ & Keterangan \\
\hline $\begin{array}{l}\text { Eksperim } \\
\text { en }\end{array}$ & 28 & 78.33 & 8.73 & 76.132 & \multirow[t]{2}{*}{1,06} & \multirow[t]{2}{*}{1,93} & \multirow[t]{2}{*}{ Homogen } \\
\hline Kontrol & 28 & 68.45 & 8.29 & 68.710 & & & \\
\hline
\end{tabular}

Berdasarkan Tabel 2 di atas, dapat ditarik kesimpulan bahwa $F_{\text {hitung }}(1,06)<F_{\text {tabel }}(1,93)$ pada taraf signifikan 5\%, maka kedua sampel memiliki varian yang homogen. Artinya bahwa analisis dengan uji parametrik memenuhi syarat.

Setelah dilakukan uji homogenitas, maka digunakan uji normalitas data untuk mengetahui data berdistribusi normal atau tidak.

\section{UJI NORMALITAS}

Tabel 3 Uji Normalitas Data Akhir Siswa

\begin{tabular}{lccl}
\hline Kelas & \multicolumn{1}{c}{$\chi_{\text {hitung }}^{2}$} & $\chi^{2}{ }_{\text {tabel }}$ & Keterangan \\
\hline Eksperimen & 50,7 & 11,070 & Normal \\
\hline Kontrol & 42,3 & 1,07 & \\
\hline
\end{tabular}

Sumber:pengolahan data primer 
Berdasarkan Tabel 3 di atas, terlihat bahwa pada kelas eksperimen $\chi_{\text {hitung }}^{2}(50.7)<\chi_{\text {tabel }}^{2}(11,070)$ dan pada kelas kontrol $\chi_{\text {hitung }}^{2}(42.3)<\chi_{\text {tabel }}^{2}(11,070)$. Hal ini menunjukkan bahwa data tes akhir pada kedua kelompok kelas berdistribusi normal.

\section{UJI HIPOTESIS}

Hasil analisis uji hipotesis data terhadap kemampuan berpikir kritis peserta didik pada mata pelajaran PPKn dapat dilihat pada Tabel 4sebagai berikut:

Tabel 4 Analisis Hipotesis Posttest

\begin{tabular}{|c|c|c|c|c|c|c|}
\hline Kelas & $\mathrm{N}$ & $\bar{x}$ & $S$ & $S^{2}$ & $t_{\text {hitung }}$ & $t_{\text {tabel }}$ \\
\hline Eksperimen & 28 & 78.45 & 8.73 & 76.132 & \multirow{2}{*}{6.214} & \multirow{2}{*}{2.021} \\
\hline Kontrol & 28 & 68.45 & 8.29 & 68.45 & & \\
\hline
\end{tabular}

Berdasarkan Tabel 4 uji t diperoleh nilai $t_{\text {hitung }}$ pada kelas eksperimen dan kelas kontrol $=6.214$ dan ttabel $=2.021$, dengan $\mathrm{dk}=\mathrm{n} 1+\mathrm{n} 2-2$ sehingga thitung $>$ tabel pada taraf signifikan 5\%. Artinya hipotesis yang diajukan dalam penelitian ini yaitu ada pengaruh model pembelajaran Cooperative Learning Tipe Time Token Arends Berbantuan Index Card Match Terhadap Hasil Belajar PPKn Siswa Kelas XI SMKN 4 Mataram.

\section{UJI $N$-GAIN}

Setelah dilakukan uji hipotesis selanjutnya dilakukan uji $\mathrm{N}$-Gain untuk mengetahui selisih atau perbedaan nilai rata-rata antara hasil Pre test dan Post test dari kelas eksperimen dan kelas kontrol. Berdasarkan hasil pengolahan uji $\mathrm{N}$-Gain dari nilai rata-rata peserta didik diperolah sebagai berikut:

Tabel 5 Hasil uji $N$-Gain tes awal dan tes akhir kelas eksperimen dan kelas kontrol

\begin{tabular}{ccccc}
\hline Kelas & $\begin{array}{c}\text { Rata-rata tes } \\
\text { akhir }\end{array}$ & $\begin{array}{c}\text { Rata-rata tes } \\
\text { awal }\end{array}$ & N-Gain & Kategori \\
\hline Eksperimen & 78.33 & 45.47 & 0,60 & Sedang \\
\hline Kontrol & 68.45 & 37.14 & 0,50 & Sedang \\
\hline Sumber:pengolahan data primer & & &
\end{tabular}

Berdasarkan Tabel 5 terlihat bahwa hasil uji $N$-Gain kelas eksperimen adalah 0,60 dengan kategori sedang dan hasil uji $\mathrm{N}$-Gain kelas kontrol adalah 0,50 dengan kategori sedang. Artinya bahwa hasil belajar siswa menggunakan model pembelajaran Cooperative Learning Tipe Time Token Arends Berbantuan Index Card Match lebih besar dibandingkan dengan hasil belajar siswa yang menggunakan model pembelajaran ceramah. 
Vol. 6 No. 1, Oktober-Maret 2019, hh. 18-26

\section{PEMBAHASAN}

Penelitian Quasi Eksperimental yang digunakan dalam penelitian ini bertujuan untuk mengetahui pengaruh model pembelajaran Cooperative LearningTipe Time Token Arends Berbantuan Index Card Match Terhadap Hasil Belajar PPKn Siswa Kelas XI SMKN 4 Mataram.

Dalam penelitian ini digunakan dua kelompok sampel yang terdiri dari dua kelas, yaitu kelas XI KC 2 sebagai kelas eksperimen, sedangkan kelas XI Boga 2 sebagai kelas kontrol. Siswa kelas eksperimen menerima perlakuan berupa model pembelajaran Cooperative Learning Tipe Time Token Arends Berbantuan Index Card Match sedangkan siswa kelas kontrol menerima perlakuan berupa model pembelajaran ceramah saja yang biasa digunakan oleh guru.

Hasil belajar yang diukur adalah hasil belajar siswa dalam mata pelajara PPKn dengan menggunakan intrumen soal berupa pilihan ganda pada materi pembelajaran "Kasus pelanggaran HAM dalam rangka pelindungan, pemajuan, dan pemenuhan HAM". Sebelum menerima perlakuan, kelas eksperimen dan kelas kontrol diberikan tes awal atau pre test terlebih dahulu untuk melihat kemampuan awal kedua kelompok tersebut. Data hasil penelitian menunjukkan untuk tes awal atau pre test, diperoleh rata-rata nilai kelas eksperimen yaitu 45.48 dan kelas kontrol yaitu 40.24. Nilai rata-rata yang diperoleh dari kedua kelompok tersebut menunjukkan bahwa hasil belajar siswa sebelum menerima perlakuan hampir sama, karena belum memahami materi soal yang diberikan pada tes awal atau pre test.

Penerapan model Cooperative Learning Tipe Time Token Arends berbantuan Index Card Matchmampu membuat siswa aktif belajar dan mengarah kepada hasil belajar siswa. Seperti yang diungkapkan oleh Budiyanto (2016:149) bahwa model ini bertujuan agar masing-masing anggota kelompok diskusi mendapatkan kesempatan untuk memberikan kontribusi dalam menyampaikan pendapat mereka dan mendengarkan pandangan serta pemikiran anggota lain. Sedangkan menurut Suprijono (2011:120) Index Card Match adalah (mencari pasangan kartu) cukup menyenangkan digunakan untuk mengulang materi pembelajaran yang telah diberikan sebelumya.

Hasil tes akhir untuk hasil belajar siswa pada kedua kelompok sampel setelah diberikan perlakuan menunjukkan bahwa hasil belajar siswa pada kedua kelompok tersebut mengalami perubahan. Rata-rata nilai tes akhir peserta didik kelas eksperimen adalah 78.33 dan rata-rata tes akhir untuk kelas kontrol adalah 68.45. Secara keseluruhan, siswa yang menerima perlakuan berupa model pembelajaran Cooperative Learning Tipe Time Token Arends Berbantuan Index Card Matchmenunjukkan perubahan nilai yang lebih tinggi dibandingkan dengan kelas kontrol yang tidak menerima perlakuan model pembelajaran Cooperative Learning Tipe Time Token Arends Berbantuan Index Card Match.

Hasil penelitian di atas menunjukkan bahwa hasil belajar PPKn siswa kelas eksperimen lebih baik dari pada kelas kontrol dikarenakan model pembelajaran Cooperative Learning Tipe Time Token Arends 
berbantuan Index Card Matchmerupakan model pembelajaran yang memberikan kesempatan kepada siswa dalam mengembangkan keterampilan sosial agar tidak mendominasi bicara sama sekali dan berani mengemukakan pendapatnya dengan mempelajari materi ajar yang sedang atau sudah dipelajari.

Hasil penelitian di atas di dukung oleh penelitian terdahulu diantaranya oleh Ma'ab(2015: 52). Dalam penelitian skripsi ini menunjukkan bahwa pembelajaran Time Token Arends yang diterapkan pada kelompok eksperimen dapat mempengaruhi hasil belajar siswa dibanding kelompok kontrol yang pembelajarnnya metode konvensional. Hasil kajian lain di dukung oleh Hendra dkk (2015) mendeskripsikan hasil penelitian menunjukkan bahwa terdapat perbedaan yang signifikan antara hasil belajar PKn kelas eksperiemen yang menerapkan dengan judul model pembelajaran Kombinasi Cooperative Learning Tipe Student TeamsAchievement Divisions Dan Index Card Match dan kelas kontrol yang menerapkan model pembelajaran seperti biasanya.

\section{SIMPULAN}

Penelitian ini dilakukan di SMKN 4 Mataram berdasarkan hasil penelitian yang telah dilakukan dengan menerapkan model pembelajaran Cooperative Learning Tipe Time Token Arends berbantuan Index Card Match terhadap hasil belajar PPKn siswa kelas XI maka dapat ditarik kesimpulan bahwa hasil perhitungan dengan uji t pada kelas XI KC 2 sebagai kelas Eksperimen dan XI Boga 2 sebagai kelas kontrol di peroleh $\mathrm{t}$ hitung=6.214, $\mathrm{t}$ tabel $=2.021$ dengan $\mathrm{dk} 28+28-2=54$ pada taraf signifikasi $5 \%$ menghasilkan nilai $\mathrm{t}_{\text {hitung }}=$ $6.214>\mathrm{t}_{\text {tabel }}=2.021$, maka dapat dinyatakan hipotesis penelitian diterima yang berarti bahwa ada pengaruh yang signifikan penerapan model pembelajaranCooperative Learning Tipe Time Token Arends berbantuan Index Card Match terhadap hasil belajar PPKn siswa kelas XI SMKN 4 Mataram.

\section{UCAPAN TERIMAKASIH}

Ucapan terimakasih disampaikan kepada Jurusan IPS FKIP Universitas Mataram dan Dewan Redaksi Jurdiksiam yang menfasilitasi dalam penelitian dan publikasi hasil kajian ini.

\section{DAFTAR PUSTAKA}

"Pendidikan Pancasila Dan Kewarganegaraan" Dari https://Mudarwan.Files.Wordpress.Com/2014/11/2Pmp-PPKn-Smp.Pdf, Di Unduh Pada Tanggal 05 Januari 2018

Budiyanto A.K. 2016. Sintaks 45 Metode Pembelajaran Dalam Students Centered Learning. Malang: Umm Press

Cook, T. D., Campbell, D. T., \& Day, A. (1979). Quasi-Experimentation: Design \& Analysis Issues For Field Settings (Vol. 351). Boston: Houghton Mifflin. 
Vol. 6 No. 1, Oktober-Maret 2019, hh. 18-26

Frintis Karianto. 2014. Kajian Pendidikan Pancasila Dan Kewarganegaraan (Ppkn),Dari:Http://Frintiskarianto.Blogspot.Co.Id/2014/09/Kajian-Pendidikan-Pancasila-Dan.Html.Di Unduh Pada Tanggal20 Desember 2017

Ibrahim, I. (2017). Perpaduan Model Pembelajaran Aktif Konvensional (Ceramah) Dengan Cooperatif (Make-A Match) Untuk Meningkatkan Hasil Belajar Pendidikan Kewarganegaraan. Suara Guru, $3(2), 199-212$.

Khusna, M. (2016). Korelasi Antara Hasil Belajar Mata Pelajaran Aqidah Akhlaq Dengan Perilaku Siswa Kelas Ix Di Mts. Darussalam Sidodadi Taman Sidoarjo (Doctoral Dissertation, Uin Sunan Ampel Surabaya).

Ma'ab, H. (2015) Pengaruh Penerapan Metode Pembelajaran Time Token Arends Terhadap Hasil Belajar Pkn Siswa Kelas Iv Sdn Pisangan 03.

Ningsih, N. (2014) Penerapan Strategi Index Card Match (ICM) Pada Pembelajaran Matematika Siswa Kelas Vii Mts Negeri Lubuklinggau Tahun Pelajaran 2014/2015.

Suprijono A. 2011. Cooperative Learning. Yogyakarta: Pustaka Pelajar.

Surakatra: Universitas Sebelas Maret

Utaminingsih, D.W.T. 2010. Upaya Peningkatan Prestasi Belajar Pkn Melalui Metode Pembelajaran ThinkPair-Share (TPS) Bagi Siswa Kelas Vii C Smpn 3 Prambanan Tahun Ajaran 2009/2010. Laporan Penelitian.

Valentina, O. F., Jampel, N., \& Murda, I. N. (2013). Pengaruh Model Pembelajaran Time Token Arends Terhadap Hasil Belajar Pkn Siswa Kelas V Sd Gugus II Kecamatan Seririt. Mimbar Pgsd, 1(1).

Wirdiati, K. (2017). Pengaruh Model Pembelajaran Kooperatif Tipe Example Non Example Berbantuan Media Puzzle Terhadap Hasil Belajar Kognitif Siswa (Doctoral Dissertation, Upt. Perpustakaan). 